\title{
Symptom management strategies used by older community-dwelling people with multimorbidity and a high symptom burden - a qualitative study
}

\author{
Jeanette Eckerblad* (D, Nana Waldréus, Åsa Johansson Stark and Lisa Ring Jacobsson
}

\begin{abstract}
Background: Older community-dwelling people with multimorbidity are often not only vulnerable, but also suffer from several conditions that could produce a multiplicity of symptoms. This results in a high symptom burden and a reduced health-related quality of life. Even though these individuals often have frequent contact with healthcare providers they are expected to manage both appropriate disease control and symptoms by themselves or with the support of caregivers. The aim of this study was therefore to describe the symptom management strategies used by older community-dwelling people with multimorbidity and a high symptom burden.
\end{abstract}

Method: A qualitative descriptive design using face-to-face interviews with 20 community-dwelling older people with multimorbidity, a high healthcare consumption and a high symptom burden. People $\geq 75$ years, who had been hospitalized $\geq 3$ times during the previous year, $\geq 3$ diagnoses in their medical records and lived at home were included. The participants were between 79 and 89 years old. Data were analysed using content analyses.

Result: Two main strategy categories were found: active symptom management and passive symptom management. The active strategies include the subcategories; to plan, to distract, to get assistance and to use facilitating techniques. An active strategy meant that participants took matters in their own hands, they could often describe the source of the symptoms and they felt that they had the power to do something to ease their symptoms. A passive symptom management strategy includes the subcategories to give in and to endure. These subcategories often reflected an inability to describe the source of the symptoms as well as the experience of having no alternative other than passively waiting it out.

Conclusions: These findings show that older people with multimorbidity and a high symptom burden employ various symptom management strategies on daily basis. They had adopted appropriate strategies based on their own experience and knowledge. Healthcare professionals might facilitate daily life for older people with multimorbidity by providing guidance on active management strategies with focus on patient's own experience and preferences.

Keywords: Content analysis, Multimorbidity, Older people, Symptom management

\footnotetext{
* Correspondence: jeanette.eckerblad@ki.se

Department of Neurobiology, Care Sciences and Society, Karolinska Institutet,

Alfred Nobels Allé 23, SE-141 83 Huddinge, Stockholm, Sweden
}

(c) The Author(s). 2020 Open Access This article is licensed under a Creative Commons Attribution 4.0 International License, which permits use, sharing, adaptation, distribution and reproduction in any medium or format, as long as you give appropriate credit to the original author(s) and the source, provide a link to the Creative Commons licence, and indicate if changes were made. The images or other third party material in this article are included in the article's Creative Commons licence, unless indicated otherwise in a credit line to the material. If material is not included in the article's Creative Commons licence and your intended use is not permitted by statutory regulation or exceeds the permitted use, you will need to obtain permission directly from the copyright holder. To view a copy of this licence, visit http://creativecommons.org/licenses/by/4.0/ The Creative Commons Public Domain Dedication waiver (http://creativecommons.org/publicdomain/zero/1.0/) applies to the data made available in this article, unless otherwise stated in a credit line to the data. 


\section{Background}

Globally, the population is aging $[1,2]$ and in some countries, such as Sweden, 25\% of the population is older than 60 years of age [3]; moreover, the group of "oldest old", people older than 80 years, is increasing $[2,4,5]$. Approximately $50-80 \%$ of people older than 65 years, and more than $70 \%$ of people older than 80 years, have been reported to suffer from multimorbidity, meaning that they have two or more concomitant medical diagnoses [6]. Multimorbidity has so far been associated with high healthcare consumption, including hospitalization and longer hospital stays, institutionalization and healthcare costs, loss of physical functioning, depression, polypharmacy, lower health-related quality of life (HrQoL), a high symptom burden and high mortality [7-10]. Chronic disease among older people is considered to be one of the largest healthcare challenges of this century, affecting both socioeconomics and the healthcare systems [11-13]. To date, healthcare organizations have not been adequately prepared or designed to meet the challenges of older people with multimorbidity $[14,15]$.

One of the public health goals for this aging society is to reduce the impact of chronic diseases [11-13]. Notwithstanding, there is still a paucity of research addressing the prevalence and management strategies of concurrent symptoms and symptom burden in older people with multimorbidity, even though this is a frequent and wellknown clinical problem $[16,17]$. People with multimorbidity report a large variation in symptoms, of which pain, dry mouth, lack of energy, and numbness/tingling in hands/feet were reported by $50 \%$ or more [10].

According to the Symptom Management Theory, the goal of symptom management is to prevent or delay the negative outcomes of symptoms through biomedical, professional and management strategies (Dodd, 2001). In community-dwelling people diagnosed with and treated for chronic diseases, the responsibility of managing symptoms on a day-to-day basis often rests with the individuals themselves [18, 19]. However, all troublesome symptoms require proper assessment and management in order to prevent, delay, or minimize a high symptom burden [19].

With a growing number of older people living at home, more knowledge on symptom management is needed to facilitate better delivery of appropriate healthcare [20]. To gain further insight into the phenomenon of living with a high symptom burden, the aim of this study was to describe the symptom management strategies used by older community-dwelling people with multimorbidity and a high symptom burden.

\section{Methods}

\section{Design}

A qualitative descriptive design using face-to-face interviews with 20 community-dwelling older people with multimorbidity and a high symptom burden. The participants were engaged in a prospective, single centre, randomized, controlled trial, the Ambulatory Geriatric Assessment: A Frailty Intervention Trail (AGe-FIT) [21].

The AGe-FIT included a selected group of 382 older people with multimorbidity and a high healthcare consumption. People $\geq 75$ years, who had been hospitalized $\geq 3$ times during the previous year, who had $\geq 3$ diagnoses in their medical records according to the International classification of diseases (ICD-10) and who lived at home were included. Living in a nursing home were excluded [21, 22]. The participants were recruited through the patient administrative system of the County Council.

Results from AGe-FIT had shown that older people with multimorbidity had reported a high symptom burden on the Memorial Symptom Assessment Scale (MSAS) [10] this triggered an interest to further describe the experiences of living with a high symptom burden [23] and to explore what symptom management strategies older people with multimorbidity use. Data from the qualitative interviews have previously been analysed and published in an article focusing on the experience of living with a high symptom burden [23]. The present study focuses on symptom management strategies. All parts of the study followed the ethical guidelines given in the Declaration of Helsinki and the study was approved by the Linkoping Regional Ethical Review Board (Dnr 2012/244-32).

\section{Study settings}

This study was conducted in Sweden where the county council and municipality are responsible for the provision of health and social care, funded by income taxes. The municipality provides home health and social care, including care provision nursing homes when needed. Home care typically includes home help services to support older people in conducting activities of daily living (ADL) and instrumental ADL. Participants were recruited from a middle-sized city (120000) in the south-east of Sweden where approximately $9 \%$ of the inhabitants are 75 years or older. In this community, health care is mainly provided by the primary care centers and one general hospital.

\section{Participants and procedure}

All participants in this study were recruited consecutively during the second-year follow-up of the Age-FIT [21]. In this study, we sought a purposive sample, only including participants having a high symptom burden, i.e. a high score on the MSAS.

The MSAS was used to describe the participants' symptom burden [24]. The MSAS includes 32 different symptoms, a four-point rating scale for severity and frequency (1-4), and five-points for distress (min-max 0- 
4). Participants who had reported a high score on the MSAS (scores $\geq 3$ per symptom on frequency, severity or distress in at least four prevalent symptoms) during the second-year follow-up of the AGe-FIT were included. No significant differences between the intervention and control group regarding symptom burden were found [25]. Participants from both groups were included in this study.

Study participants who fulfilled the inclusion criteria were sent an information letter explaining the purpose of the study immediately after completing the secondyear follow-up. Twenty patients with mean age of 84, (SD \pm 2.9 ) were included, 16 women and 4 men (Table 1 ). Fifteen of the 20 participants lived alone and of those 14 were widows and one divorced. Five were married. All participants lived in their own apartments and had contact with health care. All needed home care and/or home help services to varying degrees from the municipality or next of kin.

The participants had a high total symptom burden score, median 0.96 (range 0.31-2.27) (min-max 0-4) and a mean of $12( \pm 5.3)$ prevalent symptoms per person

Table 1 Background characteristics

\begin{tabular}{|c|c|}
\hline & $\boldsymbol{n}=20$ \\
\hline Age (yrs), mean (SD) & $84( \pm 2.9)$ \\
\hline Women n (\%) & $16(80)$ \\
\hline Lived alone $n(\%)$ & $15(75)$ \\
\hline Poor hearing with or without hearing device $\mathrm{n}(\%)$ & $7(35)$ \\
\hline Poor vision with or without glasses $n(\%)$ & $3(15)$ \\
\hline \multicolumn{2}{|l|}{ Diagnosis according to ICD-10 Chapter } \\
\hline 01. Certain infectious and parasitic diseases (A00-B99) n (\%) & $5(25)$ \\
\hline 02. Neoplasms (C00-D48) n (\%) & $9(45)$ \\
\hline $\begin{array}{l}\text { 03. Diseases of the blood and blood-forming organs and } \\
\text { certain disorders involving the immune mechanism } \\
\text { (D50-D89) } n(\%)\end{array}$ & $5(25)$ \\
\hline $\begin{array}{l}\text { 04. Endocrine, nutritional and metabolic diseases } \\
(\text { E00-E90) } n(\%)\end{array}$ & $12(60)$ \\
\hline 05. Mental and behavioural disorders (F00-F99) n (\%) & $10(50)$ \\
\hline 06. Diseases of the nervous system (G00-G99) n (\%) & $10(50)$ \\
\hline 07. Diseases of the eye and adnexa (H00-H59) n (\%) & $14(70)$ \\
\hline $\begin{array}{l}\text { 08. Diseases of the ear and mastoid process } \\
(\mathrm{H} 60-\mathrm{H} 95) \mathrm{n}(\%)\end{array}$ & $7(35)$ \\
\hline 09. Diseases of the circulatory system (100-199) n (\%) & $20(100)$ \\
\hline 10. Diseases of the respiratory system (J00-J99) n (\%) & $11(55)$ \\
\hline 11. Diseases of the digestive system (K00-K93) n (\%) & $10(50)$ \\
\hline $\begin{array}{l}\text { 12. Diseases of the skin and subcutaneous tissue } \\
\text { (L00-L99) n (\%) }\end{array}$ & $9(45)$ \\
\hline $\begin{array}{l}\text { 13. Diseases of the musculoskeletal system and connective } \\
\text { tissue (M00-M99) n (\%) }\end{array}$ & $19(95)$ \\
\hline
\end{tabular}

ICD International Classification of Diseases
[10]. Each participant experienced a large variation in symptoms (Table 2).

\section{Data collection}

All interviews were performed by the first author (JE), $\mathrm{RN}, \mathrm{PhD}$ with previous experience and formal education of performing qualitative interviews. The first interview was performed as a pilot, no changes in the interview guide were made (Additional file 1). All interviews were performed between March and September 2013. The MSAS score from each participant's most recent data collection was used to guide the interviews and each symptom was discussed one-by-one with the participants. During the interviews, the participants were asked to describe -the status of their symptoms since the last data collection, -what they did to manage that symptom, -how they had learned that management strategy and -how well that strategy worked. All interviews took place at the participants' homes and the visit lasted approximately 2 hours with small talk; the interviews ranged between 20 and $55 \mathrm{~min}$. All interviews were audiorecorded and transcribed, confidentiality was ensured by allocating a code number to each interview transcript. When 20 interviews were performed, saturation was achieved [26, 27].

\section{Data analyses}

The analysis was inductive and performed using qualitative content analysis [28]. The transcribed interviews were read through several times, and significant text units (meaning units) were identified, marked and labelled with open coding close to the participant's statements, and sorted into subcategories depending on the content (Table 3). This primary analysis was performed by two of the authors. The final structure (Fig. 1) was created after all authors had checked and reviewed the data.

\section{Result}

In accordance with the purposive sample, all participants had many concomitant diagnoses and a high symptom burden. The main strategies used by the participants were active and passive symptom management. The active strategies included, to plan, to distract, to get assistance and to use facilitating techniques, while the passive strategies included to give in and to endure.

\section{Active strategies}

When using an active strategy, the participants took matters in their own hands and felt they could do something to ease the symptom. The participants that used an active symptom management strategy could often explain or describe the source of the symptom and why they thought their strategy worked e.g. the circulation of 
Table 2 MSAS symptom burden score of older people who reported the symptom as present during the preceding week

\begin{tabular}{|c|c|c|c|}
\hline Symptom & $\begin{array}{l}\text { Number of } \\
\text { participants } \\
\text { who reported } \\
\text { the symptom } \\
n=20\end{array}$ & $\begin{array}{l}\text { Symptom } \\
\text { burden } \\
\text { score range } \\
0.90-4.0\end{array}$ & $( \pm \mathrm{SD})$ \\
\hline Lack of energy & 18 & 2.8 & $( \pm 0.75)$ \\
\hline Pain & 17 & 2.9 & $( \pm 0.62)$ \\
\hline Dry mouth & 16 & 2.7 & $( \pm 0.92)$ \\
\hline Feeling drowsy & 14 & 2.1 & $( \pm 0.67)$ \\
\hline Difficulty sleeping & 13 & 3.0 & $( \pm 0.80)$ \\
\hline Worrying & 11 & 2.7 & $( \pm 0.92)$ \\
\hline Swelling of arms or legs & 11 & 2.4 & $( \pm 1.19)$ \\
\hline $\begin{array}{l}\text { Numbness/tingling } \\
\text { in hands/feet }\end{array}$ & 10 & 2.8 & $( \pm 0.55)$ \\
\hline Feeling bloated & 10 & 3.0 & $( \pm 0.47)$ \\
\hline Shortness of breath & 10 & 3.7 & $( \pm 0.55)$ \\
\hline Dizziness & 10 & 2.2 & $( \pm 0.81)$ \\
\hline $\begin{array}{l}\text { Problems with } \\
\text { urination }\end{array}$ & 9 & 2.8 & $( \pm 0.82)$ \\
\hline Feeling sad & 8 & 3.0 & $( \pm 0.65)$ \\
\hline Cough & 8 & 2.2 & $( \pm 0.74)$ \\
\hline Lack of appetite & 7 & 2.3 & $( \pm 0.64)$ \\
\hline Feeling irritable & 7 & 2.1 & $( \pm 0.79)$ \\
\hline Itching & 6 & 2.4 & $( \pm 1.10)$ \\
\hline Feeling nervous & 6 & 2.9 & $( \pm 0.98)$ \\
\hline Difficulty concentrating & 6 & 2.6 & $( \pm 0.61)$ \\
\hline Diarrhoea & 5 & 2.8 & $( \pm 0.58)$ \\
\hline "I don't look like myself" & 5 & 2.7 & $( \pm 0.97)$ \\
\hline Sweats & 4 & 1.8 & $( \pm 0.57)$ \\
\hline Difficulty swallowing & 4 & 3.0 & $( \pm 0.98)$ \\
\hline Mouth sores & 4 & 2.5 & $( \pm 0.71)$ \\
\hline Changes in skin & 4 & 1.3 & $( \pm 1.14)$ \\
\hline Constipation & 4 & 2.2 & $( \pm 0.91)$ \\
\hline $\begin{array}{l}\text { Problems with } \\
\text { sexual interest/activity }\end{array}$ & 3 & 2.0 & $( \pm 0.91)$ \\
\hline Weight loss & 3 & 1.6 & $( \pm 1.21)$ \\
\hline Nausea & 3 & 1.8 & $( \pm 0.38)$ \\
\hline
\end{tabular}

the body was insufficient (strategy: use different physical activities), the body did not get enough oxygen (use different breathing techniques), and the nerves had somehow got trapped in the joints causing pain or tingling in hands or feet (use massage). Although their management strategy did not always make the symptom disappear altogether, it could often ease the burden temporarily or prevent the symptom from getting worse. All participants were receiving pharmacological treatment for many different diseases but, despite this, medication was
Table 2 MSAS symptom burden score of older people who reported the symptom as present during the preceding week (Continued)

\begin{tabular}{llll}
\hline Symptom & $\begin{array}{l}\text { Number of } \\
\text { participants } \\
\text { who reported } \\
\text { the symptom } \\
n=20\end{array}$ & $\begin{array}{l}\text { Symptom } \\
\text { burden } \\
\text { score range } \\
0.90-4.0\end{array}$ & $( \pm \mathrm{SD})$ \\
\hline $\begin{array}{l}\text { Change in the } \\
\text { way food tastes }\end{array}$ & 2 & 3.0 & $( \pm 1.41)$ \\
Hair loss & 2 & 3.8 & $( \pm 0.35)$ \\
Vomiting & 0 & &
\end{tabular}

The MSAS symptom burden score is the mean score of the three dimensions: frequency, severity and distress (range 0-4.0)

seldom mentioned as a method for managing their symptoms or relieving symptoms. When asked where they had learned to use those techniques, they often referred to friends, family members, something they had read in a magazine or by trial and error.

\section{To plan}

The symptoms experienced by the participants were often considered to limit life in different ways and at different levels. Careful planning of activities was an active strategy, often in detail, and was considered crucial if they were to manage symptoms and feel safe: careful pre-planning of the trip, resting before leaving the house, how to get there - would it be possible to walk, go by bus or take a taxi? How long would it take, would there be anywhere to sit down while waiting for transport? Even with careful planning their health could deteriorate rapidly, and everything would have to be cancelled due to an increased symptom burden. Cancelling at the last minute was described as problematic since they felt they let people down and disappointed them. Participants who frequently had to use the toilet could, for example, pre-investigate where to find the nearest toilet or put on an adult diaper - just in case. Another strategy, with the same goal, was to plan when different medications should be taken:

\section{"Yes, if you're going away, or like yesterday, when we attended a funeral, then I did not dare take di- uretics" (Participant 9; $[\mathrm{P}])$.}

People with dizziness could plan where they would best position themselves in a room in the event they lost their balance, fell over, or were forced to crawl to the nearest phone to get help. Before sitting down, they checked that the table and chair appeared steady or robust enough to support them when they got up again. Due to a lack of energy, it was important to limit the activities during a day, and to not be away from home for a long period of time just in case the symptom burden 
Table 3 Example of the analytical process

\begin{tabular}{|c|c|c|c|c|}
\hline Meaning unit & Condensed meaning unit & Cods & Subcategories & Categories \\
\hline $\begin{array}{l}\text { I am often away from home involved in any of my activities, it's much better } \\
\text { to be around people you know }\end{array}$ & $\begin{array}{l}\text { Commitment and company } \\
\text { ease the pain }\end{array}$ & $\begin{array}{l}\text { keeping } \\
\text { busy }\end{array}$ & To distract & $\begin{array}{l}\text { Active } \\
\text { strategy }\end{array}$ \\
\hline But hopefully it can get better now that I got a shot (cortisone) in the knee & $\begin{array}{l}\text { Turned to healthcare in hope } \\
\text { of solace }\end{array}$ & $\begin{array}{l}\text { Getting } \\
\text { support }\end{array}$ & $\begin{array}{l}\text { To get } \\
\text { assistance }\end{array}$ & $\begin{array}{l}\text { Active } \\
\text { strategy }\end{array}$ \\
\hline
\end{tabular}

increased. Not traveling great distances was also mentioned as a strategy in the event they had to quickly return home due to an increased symptom burden.

"But I do not want to travel anywhere far away, but I've been on some shorter trips and it has gone well" (P 3).

\section{To distract}

Distraction was frequently used as an active strategy especially for managing pain. Pain was extremely stressful and takes incredible amounts of energy. Therefore, it was considered important to reason with yourself and try to do something that distracts from it and makes time go faster. Distractions included crosswords, lying down and closing your eyes while reciting poems to yourself. Doing some kind of hobby was considered by some to distract from symptoms. Getting out of the home and interacting with others, instead of just being

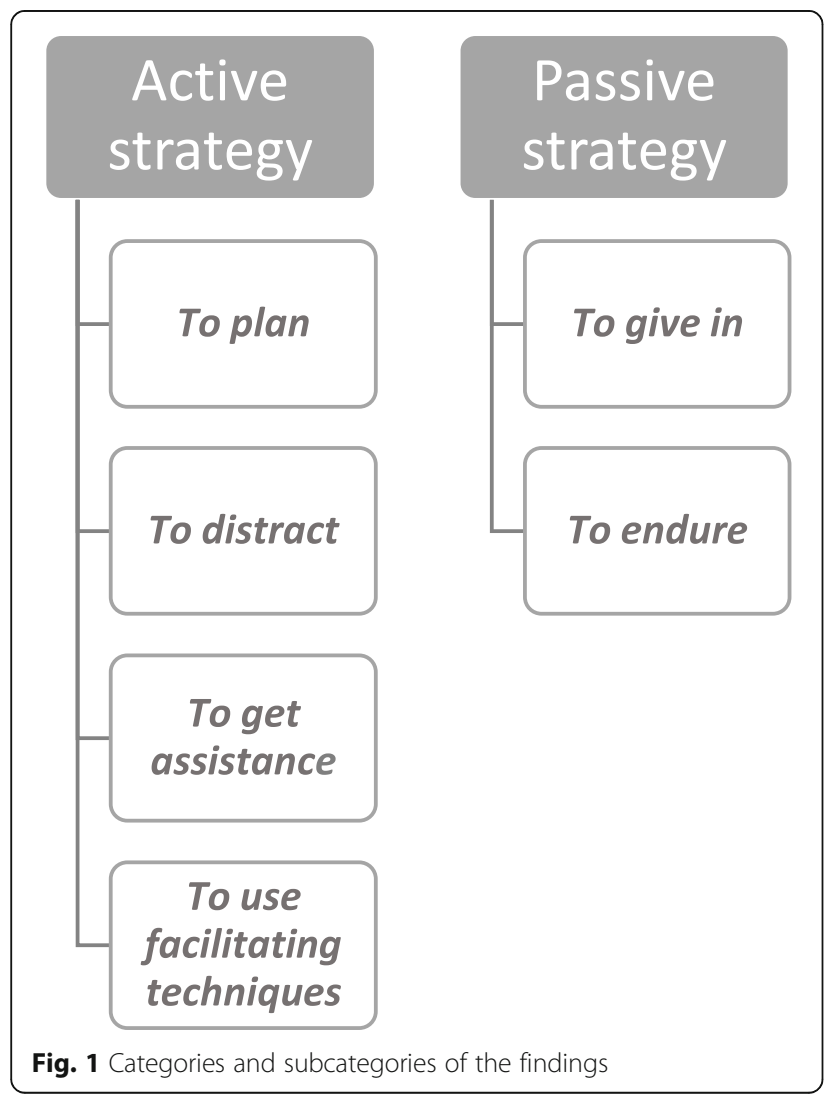

at home monitoring symptoms, was by many participants considered to be the best distraction strategy for managing symptoms:

"Well if you talk to people you might forget about the pain instead of going home all alone and just feeling it. That's really what makes the difference" (P1).

Reasoning "with yourself" was another distraction. By comparing themselves with others of the same age and situation who had an even greater symptom burden. Own symptoms were experienced easier to bear and manage when they realized that there were those who had significantly more severe symptoms:

"Well I suppose the body can't function perfectly at my age, and I see others who look very frail, so in that way I feel I'm privileged" (P3).

\section{To get assistance}

Another active strategy was to ask someone for assistance to manage their symptoms. Most often the assistance came from family or the healthcare services, but it could also be help or advice from healthcare professionals. All participants in this study had several chronic diseases necessitating frequent encounters with different healthcare professionals. The travel arrangements just to get to the clinic and back again could be too much of an effort when the symptom burden was high, and they needed assistance to be able to get there at all.

"The clinic wanted me to come down there, but I had to decline, last time I had to wait over an hour for my ride (car) to get back home. I'm just too exhausted I don't have the energy to do it" (P 5).

Some participants had symptoms necessitating assistance from relatives and family on a regular basis. Sometimes they felt forced to ask for help from friends, family or neighbours due to problems associated with the high symptom burden:

"I have my daughter who assists me with things I no longer manage myself, but it is not easy for her either, she also has her job to think about" (P1). 


\section{To use facilitating techniques}

One active strategy used by participants to ease the pain or tingling in hands or feet was different types of physical activities. When pain struck, they described it as impossible to lay down or keep still and that moving around to get the circulation going was the best option. The physical activities could involve walking, spinning/ cycling or doing squats. Other techniques were to sit up and do breathing exercises in order to get more oxygen into the system.

"When I get this pain in my chest and back, I cannot go and lie down, that will only make it worse. I'll often try to do breathing exercises" (P2).

Participants also used massage, warm socks at night, bandages, breathing exercises, TENS, relaxation, and to lie down in a specific position to ease the pain.

"Well I figured that, if I rub really hard at this area (over the ankle) it gets warm, and then somehow things seems to loosen up a bit, and the pain goes away" (P3).

To relieve symptoms of a dry mouth or from the gastrointestinal tract, they tried gargling water, excluded various foods, and tested different non-prescription drugs from the pharmacy.

Most of these exercises and methods they had learned from friends and family or through trial and error.

\section{Passive strategies}

The participants sometimes felt they had no choice when managing symptoms other than to passively give in or to endure. The participants employing this symptom management strategy could not describe the source of their symptom, they often referred to it as "no one knows, it's "just the way it is" or "the body is just totally worn out".

\section{To give in}

When the participants talked about living with multiple (concomitant) symptoms or being fatigued, they had a passive strategy. They described it as though there is nothing anyone could do about it anyway, and they associated it with old age and the aging body.

"Well I'm 86 years old so I just have to accept my fate (P 17).

A very common passive way to manage their symptoms was to sit or lie down to rest. Participants described that they took a rest in order to suppress pain, for example, and that they often experienced situations of total powerlessness.

"I suffer from a lot of pain, sometimes I start to do something (talks about baking bread), but the pain gets too intense, and I just can't finish. And when I try to do something else, it is the same story all over again" (P 17).

The participants sometimes experienced limitations in life that they could not control. In these cases, the only thing left to do was to stay at home instead of going on trips or to gatherings. Things they would like to do were no longer possible and they had to let go of interests in life.

"I was very active and dedicated once upon a time, but that has all changed now, now I'm more indifferent" (P18).

\section{To endure}

For some participants, the symptoms were so severe and debilitating that they had no alternative but to passively try to endure. They described it as a vegetative life, and they tried to cope from 1 day to the next.

"I am not really alert during the day, I'm mostly a sleep and I cannot really take any initiative of my own // I think I have outlived my own expectation by now" (P7).

Some participants blamed themselves for not being able to live a normal life. They were annoyed at themselves and considered themselves worthless and a burden for their family.

"My wife has to do everything around here now, I just sit and do nothing// I cannot even go for a walk outside anymore, my body is worn out" (P19).

\section{Discussion}

These findings contribute to our understanding of symptom management strategies used by older communitydwelling people with multimorbidity. The participants use a variety of management strategies to ease their symptom burden, which could be either active or passive. The active strategy meant that when the participant experienced an increase in a specific symptom, they used various techniques to manage this. The passive strategy meant that the participant was unable to act or avoided the situation, instead of trying to take charge.

Active and passive symptom management strategies could correspond with problem- and emotion-focused coping earlier described by Lazarus \& Folkman [29]. 
Situations when people think something constructive can be done encourages problem-focused coping, not unlike the active symptom management strategy, while the passive strategy is similar to emotion-focused coping [30]. No studies with older community-dwelling people with multimorbidity have been found reporting active and passive symptom management strategies, nor problem- and emotion-focused coping. However, there are studies within other contexts. Active strategies to manage symptoms has been found to be more common than passive strategies, such as help seeking, altering routines and distraction [31]. Hence, the passive strategies need to be identified, as they might have a negative impact on patients' health and wellbeing.

The participants in this study managed their symptoms in the best possible way they knew. By using an active strategy, the older person felt empowered and in charge, in contrast to persons using a passive strategy. People with multimorbidity have previously expressed that they shift between experiencing disruption because of the condition, and feelings of being able to accommodate the challenges the condition entails. They described constantly reassessing their prioritization of their condition [32]. We know from an earlier study in this population that people who live with a high symptom burden may have a feeling of being dependent, dejected, inadequate and limited [23].

Some participants felt that the symptoms were so severe and debilitating that they could not manage them at all, they had no alternative but to try and endure. In people with multimorbidity, the combination of physical and emotional symptoms can increase the total symptom burden, which in turn can result in a greater negative impact on daily lives [33]. Healthcare professionals must be part of the discussion if they are to raise questions on symptom management or discuss symptom maintenance to provide support and give advice. This might be important, especially in cases where the participants described that there was nothing they could do because of their old age. A recent study, reporting on adjustment to loss in old age, showed that passive adaption such as avoidance resulted in insufficient accommodation, while physical losses tackled via problem-solving and identification of new alternatives were found to be effective [34]. Passive symptom management strategies, for example to give in, appear to be inadequate whereas a combination of active management strategies, such as solving problems by planning activities and ask for assistance, appears to result in more effective symptom management. Thus, healthcare professionals should explore and support active symptom strategies among older people with multimorbidity.

One common active strategy for symptom management was to get assistance, often provided by family members or the healthcare services. In an individualized society, older people might choose to passively endure, instead of risking the potential of being a burden to their families, while others might prefer the support from society as an alternative [35, 36].

Older people with multimorbidity often have a heavy medication load and are often worried that the medication could be harmful or give unwanted side effects [37]. Therefore, it must be considered important to identify patients at risk of non-adherence to treatment, in order to reduce suffering and develop strategies to enhance adherence [38]. On the other hand, studies have reported that older people might be underdiagnosed and undertreated when it comes to e.g. pain $[39,40]$.

The importance of supporting self-management for people with multimorbidity has been increasingly highlighted as a key component of improving the overall health of this population [14]. If healthcare professionals are to support and facilitate symptom management in older people with multimorbidity, symptom self-management must be highlighted and recognized. The Symptom Management Theory [18] identifies three dimensions that should be considered for effective symptom management, (symptom experience, symptom management strategies, and symptom outcomes). Shared decision-making has been suggested to be the best way for effective management strategies to be shared between older people with multimorbidity and healthcare professionals [14]. A comprehensive approach, with a focus on personal preferences, careful interpretation of the available evidence, taking time to discuss goals and preferences including the burden of any treatment, is important [17].

The participants in this study described that the symptom could vary from day-to-day, both in occurrence and burden. Symptom management strategies may also need to change as symptoms vary over time. The knowledge of the individual's own self-management strategy might help healthcare professionals to further encourage and support these symptom management strategies to reduce symptom frequency, minimize symptom severity, and relieve symptom distress. It seems urgent to find those people whose symptoms are so severe and debilitating that they cannot cope with them at all. In these cases, home visits could provide guidance on management strategies and other necessary help.

In order to provide appropriate advice regarding symptom management, it is important that healthcare professionals take the time to listen to the individual's perception of current abilities at all meetings with the healthcare services. Previous studies have shown that a higher symptom burden is a factor related to a lower HrQoL in older people with multimorbidity resulting in functional impairment, disability, and 
depression $[9,41]$. Accessible psychiatric care, as well as regular follow-up of these patients' emotional state, have shown to be helpful [33]. Moreover, older people with multimorbidity often have a heavy treatment burden as a result of the several management plans and lifestyle changes prescribed for the various conditions [14].

\section{Methodological consideration}

The design of this study enabled us to gain a deeper understanding of a less-explored subject - symptom management strategies in older people with multimorbidity and high healthcare consumption. This lack of knowledge and evidence relates to the regular exclusion of older people from clinical trials due to their frailty and their several interfering chronic diseases [42]. Older people with multimorbidity are considered a vulnerable group and require special consideration when the subject of research. All interviews were performed in the participant's own home so that the participant could easily stop their participation at any time; this however did not occur in any of the interviews. To ensure trustworthiness of this study, the concepts of credibility, conformability, dependability and transferability have to be taken into consideration [28]. All authors participated in the final analysis process; this triangulation increases credibility and increased the rigor of the data. The findings are presented with illuminating verbatim quotations to reach confirmability [28].

Some limitations of the study must be considered. Twenty participants were interviewed in this study and even though saturation seemed to be fulfilled, additional symptom management strategies might have emerged if more interviews had been performed. However, the sample size in qualitative studies depends on required information and is often low $[27,43]$. The participants interviewed in this study were frail and weak, and some found it difficult to describe their symptom management strategy. Some interviews may have been shorter because of this, and it may have decreased the quality and richness of these interviews. Efforts were made to create optimal conditions for the interviews.

\section{Conclusions}

These findings show that older people with multimorbidity and a high symptom burden monitor their symptoms and use a variety of symptom management strategies on daily basis. They had adopted appropriate symptom management methods based on their own experience and knowledge. Active strategies meant that participants took matters in their own hands, and felt they had the power to ease their symptoms. Passive symptom management strategies however often meant an inability to act, and the experience of having no alternative but to passively give in or to endure. Healthcare professional might facilitate daily life for older people with multimorbidity by providing guidance on management strategies with focus on patient's own experience and preferences.

\section{Supplementary information}

Supplementary information accompanies this paper at https://doi.org/10. 1186/s12877-020-01602-y.

Additional file 1. Interview guide.

\section{Abbreviations}

HrQoL: Health related Quality of Life; MSAS: Memorial Symptom Assessment Scale; P: Participant

\section{Acknowledgements}

We especially thank the participants in this study for sharing their symptom management strategies while living with a high symptom burden.

\section{Authors' contributions}

Study design of the work: JE, NW, ÅJS, LRJ. Data collection: JE. Primary data analysis: JE, LRJ. Drafting the work or revising it critically for important intellectual content: JE, NW, ÅJS, LRJ. Final approval of this version: JE, NW, ÅS, LRJ. The manuscript has been read and approved by all authors named therein.

\section{Funding}

Funding was provided by the Signe and Olof Wallenius Trust Fund. The funding sources were independent and had no influence on collection, analysis, and interpretation of data or in writing the manuscript. Open access funding provided by Karolinska Institute.

\section{Availability of data and materials}

The datasets used and/or analysed during the current study are available from the corresponding author on reasonable request.

\section{Ethics approval and consent to participate}

Eligible older people received an invitation letter by post and were contacted by telephone to provide verbal informed consent to participate in the study. A registered nurse made home visits to obtain written informed consent and to collect data. The present study complies with the Declaration of Helsinki and was approved by the Regional Ethics Committee in Linköping (Regionala Etikprövningsnämnden i Linköping), Sweden (Dnr 2012/244-32)

\section{Consent for publication}

In the written informed consent, participants also consent to publish the obtained data.

\section{Competing interests}

The authors declare that they have no competing interests.

Received: 5 October 2019 Accepted: 4 June 2020

Published online: 15 June 2020

\section{References}

1. Lanzieri G. The greying of the baby boomers. Eurostat. 2011;23:1-2 Available at: http://epp.eurostat.ec.europa.eu/cache/ITY_OFFPUB/KS-SF-11-023/EN/KSSF-11-023-EN.PDF

2. Christensen $K$, Doblhammer G, Rau R, Vaupel J. Ageing populations: the challenges ahead. Lancet. 2009;374(9696):1196-208.

3. Statistiska Centralbyrån (SCB) [https://www.scb.se/en/]. Accessed 12 Nov 2018.

4. World population prospects: the 2017 revision, volume I: comprehensive tables (ST/ESA/SER.A/399) [https://esa.un.org/unpd/wpp/Publications/Files/ WPP2017_Volume-I_Comprehensive-Tables.pdf]. Accessed 12 Nov 2018. 
5. Pickard S. Frail bodies: geriatric medicine and the constitution of the fourth age. Sociol Health IIIness. 2014;36(4):549-63.

6. Boeckxstaens P, De Graaf P. Primary care and care for older persons: position paper of the European forum for primary care. Qual Prim Care. 2011;19(6):369-89.

7. Glynn LG, Valderas JM, Healy P, Burke E, Newell J, Gillespie P, Murphy AW. The prevalence of multimorbidity in primary care and its effect on health care utilization and cost. Fam Pract. 2011;28(5):516-23.

8. Vogeli C, Shields AE, Lee TA, Gibson TB, Marder WD, Weiss KB, Blumenthal D. Multiple chronic conditions: prevalence, health consequences, and implications for quality, care management, and costs. J Gen Intern Med. 2007:22:391-5.

9. Klompstra L, Ekdahl AW, Krevers B, Milberg A, Eckerblad J. Factors related to health-related quality of life in older people with multimorbidity and high health care consumption over a two-year period. BMC Geriatr. 2019;19(1): 187.

10. Eckerblad J, Theander K, Ekdahl A, Unosson M, Wirehn AB, Milberg A, Krevers B, Jaarsma T. Symptom burden in community-dwelling older people with multimorbidity: a cross-sectional study. BMC Geriatr. 2015;15(1):1.

11. World Health Organization. Global status report on noncommunicable diseases. 2014.

12. Johnston MC, Crilly M, Black C, Prescott GJ, Mercer SW. Defining and measuring multimorbidity: a systematic review of systematic reviews. Eur J Pub Health. 2018;29:182-9.

13. Salive ME. Multimorbidity in older adults. Epidemiol Rev. 2013;35:75-83.

14. Wallace E, Salisbury C, Guthrie B, Lewis C, Fahey T, Smith SM. Managing patients with multimorbidity in primary care. Br Med J. 2015;350:h176.

15. Farmer C, Fenu E, O'Flynn N, Guthrie B. Clinical assessment and management of multimorbidity: summary of NICE guidance. Br Med J. 2016; 354:14843.

16. Combs S, Kluger BM, Kutner JS. Research priorities in geriatric palliative care: nonpain symptoms. J Palliat Med. 2013;16(9):1001-7.

17. Petrillo LA, Ritchie CS. The challenges of symptom management for patients with multimorbidity in research and practice: a thematic review. Prog Palliat Care. 2016;24(5):262-7.

18. Dodd M, Janson S, Facione N, Faucett J, Froelicher ES, Humphreys J, Lee K, Miaskowski C, Puntillo K, Rankin S, Taylor D. Advancing the science of symptom management. J Adv Nurs. 2001;33(5):668-76.

19. Humphreys J, Janson S, Donesky DA, Dracup K, Lee KA, Puntillo K, Faucett JA, Aouizerat B, Miaskowski C, Baggot C, Carrieri-Kohlman V, Barger M, Franck L, Kennedy C, The University of California, San Francisco (UCSF) School of Nursing Symptom Management Faculty Group. Chapter 7. Theory of Symptom Management. In: Smith MJL, Patricia R, editors. Middle range theory for nursing. 3rd ed. New York: Springer Publishing Co; 2014. p. 141-65.

20. Elias T, Lowton K. Do those over 80 years of age seek more or less medica help? A qualitative study of health and illness beliefs and behaviour of the oldest old. Sociol Health IIIn. 2014;36(7):970-85.

21. Ekdahl AW, Wirehn AB, Alwin J, Jaarsma T, Unosson M, Husberg M, Eckerblad J, Milberg A, Krevers B, Carlsson P. Costs and effects of an ambulatory geriatric unit (the AGe-FIT study): a randomized controlled trial. J Am Med Dir Assoc. 2015;16(6):497-503.

22. Mazya AL, Eckerblad J, Jaarsma T, Hellström I, Krevers B, Milberg A, Unosson M, Westöö A, Ekdahl A. The ambulatory geriatric assessment - a frailty intervention trial (AGe-FIT) - a randomised controlled trial aimed to prevent hospital readmissions and functional deterioration in high risk older adults: a study protocol. Eur Geriatr Med. 2013;4(4):242-7.

23. Eckerblad J, Theander K, Ekdahl A, Jaarsma T, Hellstrom I. To adjust and endure: a qualitative study of symptom burden in older people with multimorbidity. Appl Nurs Res. 2015;28(4):322-7.

24. Zambroski CH, Moser DK, Bhat G, Ziegler C. Impact of symptom prevalence and symptom burden on quality of life in patients with heart failure. Eur J Cardiovasc Nurs. 2005;4(3):198-206

25. Eckerblad J, Theander K, Ekdahl AW, Jaarsma T. Symptom trajectory and symptom burden in older people with multimorbidity, secondary outcome from the RCT AGe-FIT study. J Adv Nurs. 2016;72(11):2773-83.

26. Glaser BG, Strauss AL, Strutzel E. The discovery of grounded theory; strategies for qualitative research. Nurs Res. 1968;17(4):364.

27. Weller SC, Vickers B, Bernard HR, Blackburn AM, Borgatti S, Gravlee CC, Johnson JC. Open-ended interview questions and saturation. PLoS One. 2018;13:6
28. Graneheim UH, Lundman B. Qualitative content analysis in nursing research: concepts, procedures and measures to achieve trustworthiness. Nurse Educ Today. 2004;24(2):105-12.

29. Lazarus R, Folkman S. Stress, appraisal and coping. New York: Springer Publishing Company; 1984

30. Folkman S, Lazarus RS. An analysis of coping in a middle-aged community sample. J Health Soc Behav. 1980;1:219-39.

31. Schulz PS, Zimmerman L, Pozehl B, Barnason S, Nieveen J. Symptom management strategies used by elderly patients after coronary artery bypass surgery. Appl Nurs Res. 2011;24(2):65-73.

32. Morris RL, Sanders C, Kennedy AP, Rogers A. Shifting priorities in multimorbidity: a longitudinal qualitative study of patient's prioritization of multiple conditions. Chronic Illness. 2011;7(2):147-61.

33. Liddy C, Blazkho V, Mill K. Challenges of self-management when living with multiple chronic conditions systematic review of the qualitative literature. Can Fam Physician. 2014;60(12):1123-33.

34. Thumala D, Gajardo B, Gómez C, Arnold-Cathalifaud M, Araya A, Jofré P, Ravera V. Coping processes that foster accommodation to loss in old age. Aging Ment Health. 2018;24:1-8.

35. Berggren H, Eklund K, Trädgårdh L. The Nordic way, Shared norms for the new reality. Davos: World Economic Forum; 2011.

36. Johansson L, Long H, Parker MG. Informal caregiving for elders in Sweden: an analysis of current policy developments. J Aging Soc Policy. 2011;23(4): 335-53.

37. Summer Meranius M, Engstrom G. Experience of self-management of medications among older people with multimorbidity. J Clin Nurs. 2015; 24(19-20):2757-64.

38. Cicolini G, Comparcini D, Flacco ME, Capasso L, Masucci C, Simonetti V. Selfreported medication adherence and beliefs among elderly in multitreatment: a cross-sectional study. Appl Nurs Res. 2016;30:131-6.

39. Landi F, Onder G, Cesari M, Gambassi G, Steel K, Russo A, Lattanzio F, Bernabei R. Pain management in frail, community-living elderly patients. Arch Int Med. 2001;161(22):2721-2749 2726p.

40. Abdulla A, Adams N, Bone M, Elliott AM, Gaffin J, Jones D, Knaggs R, Martin D, Sampson L, Schofield P. Guidance on the management of pain in older people. Age Ageing. 2013;42(Suppl 1):i1-i57.

41. Marengoni A, Angleman S, Melis R, Mangialasche F, Karp A, Garmen A, Meinow B, Fratiglioni L. Review: aging with multimorbidity: a systematic review of the literature. Ageing Res Rev. 2011:10:430-9.

42. Ritchie CS, Zulman DM. Research priorities in geriatric palliative care: multimorbidity. J Palliat Med. 2013;16(8):843-7.

43. Polit DF. Nursing research: generating and assessing evidence for nursing practice. 10th ed. Philadelphia: Wolters Kluwer; 2016

\section{Publisher's Note}

Springer Nature remains neutral with regard to jurisdictional claims in published maps and institutional affiliations.

Ready to submit your research? Choose BMC and benefit from:

- fast, convenient online submission

- thorough peer review by experienced researchers in your field

- rapid publication on acceptance

- support for research data, including large and complex data types

- gold Open Access which fosters wider collaboration and increased citations

- maximum visibility for your research: over $100 \mathrm{M}$ website views per year

At $\mathrm{BMC}$, research is always in progress.

Learn more biomedcentral.com/submissions 